\title{
MEKANISME PEMBERIAN HADIAH SEBAGAI PENGERAT HUBUNGAN DIPLOMATIK DALAM WARKAH KESULTANAN MELAYU BIMA KEPADA BELANDA
}

\section{(Mechanism of Gift-Giving through Diplomatic Letters from the} Bima Sultanate to the Netherlands)

\author{
Salmah Jan Noor Muhammad* \\ salmahjan@upm.edu.my \\ Che Nuraini Che Puteh \\ missemynuraini94@gmail.com
}

Jabatan Bahasa Melayu, Fakulti Bahasa Moden dan Komunikasi, Universiti Putra Malaysia

Corresponding author (Pengarang koresponden): *

To cite this article (Rujukan artikel ini): Salmah Jan Noor Muhammad $\&$ Che Nuraini Che Puteh. (2021). Mekanisme pemberian hadiah sebagai pengerat hubungan diplomatic dalam warkah kesultanan Melayu Bima kepada Belanda. Malay Literature, 34(1), 21-42. http://doi.org. 10.37052/ml34(1)no2

\begin{tabular}{|lllllll|}
\hline $\begin{array}{l}\text { Received: } \\
\text { Peroleh: }\end{array}$ & 1/4/2021 & $\begin{array}{l}\text { Revised: } \\
\text { Semakan }\end{array}$ & 8/5/2021 & $\begin{array}{l}\text { Accepted: 11/5/2021 } \\
\text { Terima: }\end{array}$ & $\begin{array}{l}\text { Publish online: } \\
\text { Terbit dalam talian: }\end{array}$ & 3/6/2021 \\
\hline
\end{tabular}

\begin{abstract}
Abstrak
Kerajaan Bima merupakan antara kerajaan Islam yang mempunyai hubungan erat dengan Belanda. Hubungan ini terjalin dan semakin rancak apabila Bima diperintah oleh Sultan Abdul Hamid. Sultan Abdul Hamid merupakan pemerintah yang aktif yang menguruskan hubungan Bima dan Belanda. Pengukuhan hubungan tersebut berlaku menerusi penghantaran warkah yang merupakan medium penting pada masa tersebut untuk menyampaikan pesanan. Penulisan ini mengenal pasti warkah diplomatik yang dihantar oleh Bima kepada Belanda dan menganalisis jenis iringan hadiah yang diberikan sebagai mekanisme diplomatik. Bagi memperoleh data ini, suatu kajian kepustakaan telah dilakukan untuk memperoleh
\end{abstract}

(C) Dewan Bahasa dan Pustaka. 2021. This work is licensed under the term of the Creative Commons Attribution (CC BY) (http://creative commons.org/licenses/by/4.0/) 
data kajian dan menggunakan Teori Diplomasi Islam yang diperkenalkan oleh Ahmed Musa (2009). Hasil kajian menunjukkan bahawa terdapat kepelbagaian hadiah yang diberikan oleh Bima kepada Belanda untuk mengukuhkan hubungan antara kedua-dua buah kerajaan. Kajian ini diharap dapat menyumbang kepada pengkajian dan penelitian warkah kesultanan Melayu dan seterusnya menggalakkan dapatan baharu serta memperkembang ilmu tentang warkah kesultanan Melayu.

Kata kunci: Bima, Belanda, hadiah, warkah, diplomatik

\begin{abstract}
The Bima Sultanate is one of the Islamic kingdoms that had close relations with the Netherlands. This relationship was established and became more vibrant when Bima was ruled by Sultan Abdul Hamid. Sultan Abdul Hamid was an active monarch when it came to managing Bima's relations with the Netherlands. The relationship was strengthened through the sending of epistles which were an important medium for sending messages at the time. Thus, this article will identify diplomatic epistles from Bima to the Netherlands, as well as analysing the accompanying gifts. This article uses the library research method and utilizes the Theory of Islamic Diplomacy of Ahmed Musa (2009). The results show that there is a diversity of gifts given by Bima to the Netherlands in order to strengthen the relationship between the two kingdoms. This study hopes to contribute to the research and study of epistles from the Malay sultanates, and thereby to encourage new findings, as well as the development of new knowledge about epistles from Malay sultanates.
\end{abstract}

Keywords: Bima, Netherlands, letters, Malay, diplomatic

\title{
PENDAHULUAN
}

Kerajaan Bima merupakan wilayah yang memainkan peranan penting dalam sejarah Islam di Nusantara dan juga sebuah kerajaan yang mempunyai ekonomi yang kukuh. Menurut M. Hilir (2004), Bima terletak di kawasan yang strategik, iaitu di tengah kepulauan Nusantara dan mempunyai sumber alam seperti kayu soga (kayu untuk pemberi warna), rotan, damar, kuda, kerbau, dan lain-lain. Marwati dan Nugroho (2008) pula menyatakan bahawa kerajaan Bima merupakan sebuah kerajaan yang amat menonjol di Asia Tenggara ketika bermulanya pemerintahan Islam. Hal ini telah membuka peluang kepada pedagang luar untuk menjalinkan hubungan dengan kerajaan 
SALMAH JAN NOOR MUHAMMAD AND CHE NURAINI CHE PUTEH

Jadual 1 Salasilah kesultanan Bima (Haris, Tawalinuddin, 2006).

\begin{tabular}{|c|l|l|c|}
\hline $\begin{array}{c}\text { Sultan } \\
\text { Bima }\end{array}$ & \multicolumn{1}{|c|}{ Nama } & \multicolumn{1}{|c|}{ Gelaran } & Tempoh \\
\hline 1 & Abdul Kahir & Mantau Wata Wadu & $1620-1640$ \\
\hline 2 & $\begin{array}{l}\text { I Ambela Abi'l Khair } \\
\text { Sirajuddin }\end{array}$ & Mantau Uma Jati & $1640-1682$ \\
\hline 3 & Nuruddin Abu Bakar All Syah & Mawa'a Paju & $1682-1687$ \\
\hline 4 & Jamaluddin Ali Syah & Mawa'a Romo & $1687-1696$ \\
\hline 5 & Hasanuddin Muhammad Syah & Mabata Bo'u & $1696-1731$ \\
\hline 6 & Alauddin Muhammad Syah & Manuru Daha & $1731-1748$ \\
\hline 7 & Kamalat Syah & Rante Patola Sitti Rabi'ah & $1748-1751$ \\
\hline 8 & Abdul Kadim Muhammad Syah & Mawa'a Taho & $1751-1773$ \\
\hline 9 & Abdul Hamid Muhammad Syah & Mantau Asi Saninu & $1773-1817$ \\
\hline 10 & Ismail Muhammad Syah & Mantau Dana Sigi & $1817-1854$ \\
\hline 11 & Abdullah & Mawa'a Adil & $1854-1868$ \\
\hline 12 & Abdul Aziz & Mawa'a Sampela & $1868-1881$ \\
\hline 13 & Ibrahim & Ma Taho Parange & $1881-1915$ \\
\hline 14 & Muhamad Salahuddin & Marrbora di Jakarta & $1915-1951$ \\
\hline
\end{tabular}

Bima termasuklah VOC (Verenigde Oost Indische Compagnie, Perusahaan Dagang Hindia Timur).

Kesultanan Bima telah diperintah oleh 14 orang raja termasuklah Sultan Abdul Hamid Muhammad Syah pada tahun 1773-1718, iaitu pemerintah yang kesembilan manakala Sultan Muhammad Salahuddin ialah sultan yang terakhir dalam sistem pemerintahan kesultanan ini. Rouffaer (1910) mengatakan bahawa kerajaan Bima meliputi bahagian timur pulau Sumbawa, Flores Barat (Manggarai) dan pulau-pulau kecil di Selat Alas dan sekitarnya. Sementara itu, Tawalinuddin, Susanto dan Triana (1997) menunjukkan bahawa kerajaan Bima menguasai beberapa daerah antaranya termasuklah Pulau Sumbawa, Larantuka, Ende, Sawu, Komodo, Solor, Menggarai dan Sumba.

Menurut van Hollander (1908) kedudukan Bima menggambarkan sempadan antara Bima dan Dompo dengan sebuah garis pada $118^{\circ} 37^{\prime}$ di pantai utara ke arah selatan melalui Gunung WawoSahe ke arah $118^{\circ} 38^{\prime} 30^{\prime}$ di pantai selatan. Dalam catatan Kerajaan Bima, sempadan tersebut bermula dari Doro Dewa pada $118^{\circ} 31^{\prime}$ di pantai utara terus ke selatan melalui puncak Gunung Doro Mandompo menuju ke Kampung Pajo, lalu ke arah selatan 

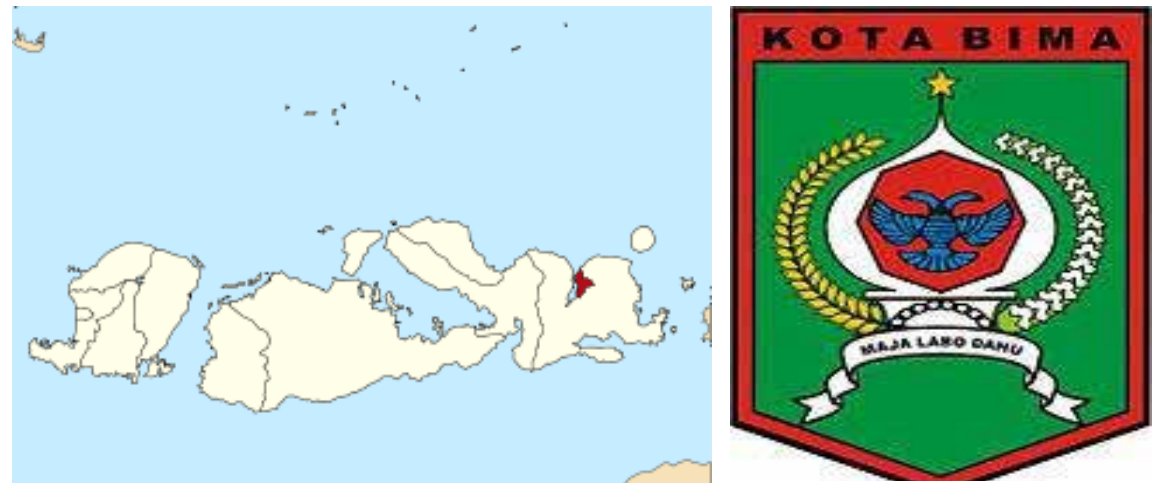

Rajah 1Peta Wilayah Bima di Nusa Tenggara Barat Berkoordinat: $118^{\circ} 44^{\prime}-$ $119^{\circ} 22^{\prime}$ LS, $8^{\circ} 8^{\prime}-8^{\circ} 57^{\prime}$ BT dan Logo Negeri Bima.

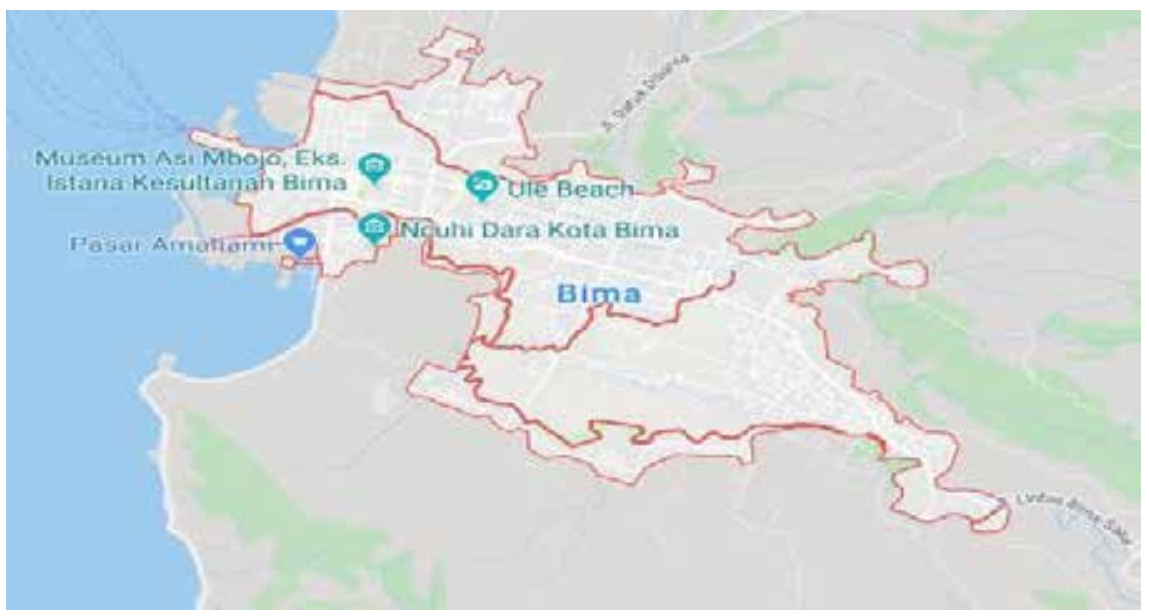

Rajah 2 Wilayah Bima

(Sumber: Google)

menuju ke Wadu Nteli Mayaga, Wadu Lepi, kemudian membelok ke barat menuju ke Wadu Udu, dekat Kampung Dompo bernama Daha. Seterusnya, dari Daha ke arah tenggara menuju ke Wadu Suga dan akhirnya ke arah selatan ke muara Sungai Sori Soma di pantai laut selatan (Samudera Hindia) pada $118^{\circ} 34^{\prime}$ (Morris, 1890). Pada 2001, kerajaan Bima dikenali sebagai Kota Bima dan diuruskan bersama-sama dengan negeri lain yang terdapat di Nusa Tenggara Barat, Indonesia dan mempunyai sebanyak 14 buah wilayah seperti yang dicatatkan dalam rekod Pulau Sumbawa News (2015). Kota 
Bima ini terus berkembang sejajar dengan perkembangan masyarakat Bima yang semakin meluas. Pada 2006, Kota Bima telah ditukar nama sebagai sebuah Ibu Kota Bima yang berpusat di Wilayah Woha dengan tambahan sebanyak 4 buah lagi wilayah baharu.

\section{WARKAH DIPLOMATIK BIMA KEPADA BELANDA}

Penulisan ini akan membincangkan secara asas berkenaan dengan warkah kesultanan Melayu Bima yang ditulis dan dihantar kepada Tuan Gurnadur Jenderal Van Der Capellen yang mewakili kerajaan Belanda. Perkara asas ini akan dirungkaikan berdasarkan sejarah warkah tersebut, iaitu merangkumi tarikh, pengirim dan penerima serta kandungan warkah yang merekodkan hubungan antara kedua-dua buah kerajaan. Salah satu inisiatif kerajaan Bima dalam usaha menjaga kedaulatannya adalah dengan membentuk kesatuan bersama-sama Belanda. Permulaan kepada hubungan ini adalah melalui penghantaran sembilan pucuk warkah kepada kerajaan Belanda. Warkah ini saling berkaitan antara satu sama lain dan memfokuskan kepentingan kedua-dua buah kerajaan. Kerajaan Bima terkenal sebagai pemerintah yang jujur, dan menjalankan perniagaan kayu sepang dengan rancak pada abad ke-18 dan ke-19, manakala kerajaan Belanda dikenali sebagai sebuah negara berdaulat serta mempunyai pengaruh yang dominan terhadap kerajaan Melayu. Kesannya, hubungan ini telah membawa kepada suatu anjakan paradigma yang menjurus kepada hubungan diplomatik atas keperluan masing-masing.

Sebanyak 33 warkah dikenal pasti dimiliki oleh Bima yang dikirimkan kepada Belanda dan kebanyakannya ditulis pada zaman pemerintahan Sultan Abdul Hamid. Kini, warkah tersebut didokumentasi dan disimpan dalam koleksi Perpustakaan Universiti Leiden, Belanda. Daripada penelitian, kandungan warkah ini mempunyai tujuan penghantaran yang berbeza mengikut situasi yang berlaku pada masa tersebut. Misalnya, kiriman warkah dalam bentuk perjanjian antara kerajaan Bima dengan kerajaan-kerajaan di sekitarnya seperti Flores Barat (Manggarai). 33 warkah ini termasuklah Surat A, Surat B, Surat $C$, Surat D, Surat E, Surat F, Surat G, Surat H, Surat I, Surat J, Surat K, Surat L, Surat M, Surat $N$, Surat $O$ dan Surat $P$. Seterusnya Surat $Q$, Surat $R$, Surat $S$, Surat T, Surat $U$, Surat V, Surat $W$, Surat X, Surat Y, Surat Z, Surat A1, Surat B2, Surat C3, Surat D4, Surat E5, Surat F6 dan Surat G7. Namun begitu, hanya sembilan pucuk warkah yang dikenal pasti bersifat diplomatik. Sembilan pucuk warkah tersebut adalah seperti dalam Jadual 2. Melalui pengamatan awal, penulisan dan kajian tentang warkah kesultanan Melayu Bima masih lagi terbatas perbincangannya dan belum disebarkan 
Jadual 2 Sembilan pucuk warkah diplomatik.

\begin{tabular}{|c|l|l|}
\hline Bil. & \multicolumn{1}{|c|}{ Nama Warkah } & \multicolumn{1}{c|}{ Tahun } \\
\hline 1. & Warkah B & 20 Julai 1790 \\
\hline 2. & Warkah D & 23 Julai 1792 \\
\hline 3. & Warkah E & 25 Ogos 1792 \\
\hline 4. & Warkah L & 30 September 1798 \\
\hline 5. & Warkah P & 3 Oktober 1800 \\
\hline 6. & Warkah Q & 18 September 1801 \\
\hline 7. & Warkah V & 21 September 1802 \\
\hline 8. & Warkah W & 2 September 1803 \\
\hline 9. & Warkah G7 & 21 Julai 1820 \\
\hline
\end{tabular}

kepada khalayak dengan meluas. Antara kajian yang dikenal pasti ialah Suryadi (2010) yang menekankan aspek filologi dan memfokuskan kepada 10 warkah Sultan Abdul Hamid Muhammad Syah. Penulisan ini merupakan antara sumbangan untuk memperluas bacaan tentang warkah Bima dengan membincangkan sudut diplomatik yang merupakan perkara penting dalam sesebuah pemerintahan. Kajian ini menggunakan kaedah kepustakaan yang merangkumi empat tatacara, iaitu mengumpul, memilih, menganalisis dan merumuskan data. Pada tahap pengumpulan data, aktiviti yang dilakukan adalah dengan mengumpul warkah-warkah kiriman Bima kepada Belanda. Seterusnya, memilih warkah yang bersifat diplomatik dan selari dengan objektif kajian. Sementara itu, pada tahap analisis data, kajian mencatatkan dan membincangkan perkara yang berkaitan dan dominan berdasarkan objektif kajian dan akan membuat rumusan dapatan yang diperoleh.

Bagi mengukuhkan analisis kajian, Teori Diplomasi Islam yang diperkenalkan oleh Ahmed Musa pada 2009 digunakan sebagai asas penelitian. Teori ini memfokuskan mekanisme diplomatik Islam yang diaplikasikan oleh Rasulullah SAW kepada kerajaan sekitar dalam dakwah Islam, iaitu penghantaran warkah, memberi dan menerima hadiah, penguasaan bahasa asing dan perlindungan keselamatan atau kekebalan. Mekanisme ini juga menekankan adab dan etika semasa menjalinkan hubungan diplomatik. Perkara ini penting untuk mengukuhkan hubungan dan seterusnya mengelakkan perselisihan faham. Selain itu, mekanisme ini menekankan hubungan baik antara satu negara dengan negara lain. Elemen pemberian hadiah difokuskan dalam perbincangan ini kerana elemen ini sangat dekat dengan tujuan utama teori ini dihasilkan. 


\section{DESKRIPSI RINGKAS KANDUNGAN WARKAH}

Keperibadian sembilan pucuk warkah diplomatik yang dikirimkan oleh Bima dideskripsikan secara ringkas seperti yang berikut.

\section{Keperibadian Warkah B}

Warkah $B$ merupakan warkah pertama yang ditulis oleh kerajaan Bima kepada kerajaan Belanda. Penghantaran warkah ini adalah pada 20 Julai 1790 bersamaan 8 Zulkaedah 1204. Namun begitu, warkah ini hanya sampai pada 20 September 1790 kerana faktor perjalanan yang memakan masa agak panjang. Kod naskhah ialah Cod.Or.2240-Ia (2) [no. 13]. Warkah ini ditulis sebagai wakil Raja kepada Sultan Abdul Hamid Muhammad Syah. Warkah $B$ juga merupakan warkah yang tertua dalam kumpulan warkah yang lain. Warkah ini dihantar kepada yang berkuasa Tuan Gurnadur Jenderal Yang Maha Mulia Rat Van [In]dia dan kepada Baron Van Der Capellen (Warkah G7) yang merupakan pemegang atau pentadbir Belanda pada ketika itu. Penulisan surat termasuklah dengan waad atau perjanjian untuk bersahabat dengan Belanda yang sangat terkenal pada masa itu.

Pengiriman warkah ini adalah sebagai pemberitahuan kepada pihak Belanda bahawa Bima telah memberikan maklum tentang warkah yang dihantar oleh TGJ (Tuan Gurnadur Jenderal) dan angkatannya telah sampai dengan selamat di negeri Bima. Kerajaan Bima meminta bantuan keselamatan dan kebajikan kepada kompeni Belanda untuk memakmurkan lagi negerinya. Perjanjian akad setia telah dilakukan untuk mengikat negeri Bima dan Belanda agar dapat bersatu di bawah naungan kuasa Belanda yang gah.

\section{Keperibadian Warkah D}

Warkah D berkod Cod.Or.2240-Ia (14) [no. 78] merupakan warkah yang ditulis pada 23 Julai 1792 bersamaan dengan 3 Zulhijah 1206 dan diterima di Belanda pada tarikh 9 November 1792. Warkah ini dihantar oleh Raja Bima kepada Tuan Gurnadur Jenderal sebagai balasan kepada surat Tuan Gurnadur Jenderal sebelum ini. Tuan Gurnadur Jenderal tidak ingin pihak kerajaan Bima membuat sebarang perhubungan atau aktiviti berjual beli dengan kerajaan Inggeris. Pada masa tersebut, kerajaan Inggeris sangat aktif menjalankan perniagaan dan bertujuan menjadikan Tanah Melayu sebagai hub perdagangan perkapalan. Bagi meredakan kemarahan kerajaan Belanda, maka sultan Bima telah menghantar surat pujukan dan memberikan keputusan tidak akan menjalankan sebarang perdagangan dengan kerajaan Inggeris. 
Kerajaan Bima di bawah pemerintahan Sultan Abdul Hamid sangat teliti dan amanah terhadap janji baginda dengan mana-mana negeri yang menjalankan perniagaan bersamanya. Oleh itu, kebaikan yang ditunjukkan oleh pihak Bima ini seringkali diambil kesempatan oleh Belanda. Warkah ini juga sebagai pengukuh hubungan antara kerajaan Bima dan Belanda. Hal ini menjadikan hubungan antara kedua-dua negara ini sangat erat dan saling menghantar hadiah sebagai tanda persahabatan. Pemberian hadiah oleh Sultan Abdul Hamid telah diletakkan di bawah pantauan Kapiten De Groot yang bertanggungjawab, dan beliau menjadi kapten kapal pada ketika itu.

\section{Keperibadian Warkah E}

Pada 25 Ogos 1792 bersamaan dengan 7 Muharam 1207, warkah E ini telah ditulis oleh kerajaan Bima kepada kerajaan Belanda dan telah diterima oleh kerajaan Belanda pada tarikh 3 September 1793 yang digelar sebagai Algeemeen Secretariaat Batavia. Penyimpanan warkah ini di Perpustakaan Universiti Leiden (Universiteitsbibliotheek) yang digelar sebagai UB dilakukan dengan menggunakan kod khas, iaitu Cod.Or.2242-II (4) [no. 98]. Warkah ini dikirimkan kepada Tuanku Jenderal sebagai balasan surat yang telah dihantar oleh kerajaan Belanda, namun tiada huraian atau pernyataan yang lebih rinci tentang faktor warkah tersebut dihantar. Hanya warkah balas daripada Bima yang terperinci dan mempunyai maklumat. Dalam warkah ini, dimaklumkan tentang fetor yang bernama Cornelis Meurs telah meninggal dunia pada hari yang ke-15 Ramadan.

Pihak Sultan Abdul Hamid telah meminta Gurnadur di negeri Mengkasar untuk mencari ganti fetor yang mampu memberikan kerjasama dan saling bermuafakat untuk menjaga keamanan kedua-dua belah pihak. Oleh itu, Gurnadur Mengkasar telah menggantikan seorang onder Kopmen yang bernama Adam van Rossem. Beliau bekerja di Bima dari tahun 1798 sehingga tahun 1801, iaitu selama 3 tahun. Akhirnya, semua permasalahan yang berlaku pada ketika itu dapat diselesaikan dengan baik oleh kedua-dua belah pihak. Perhubungan menjadi lebih rapat dan mesra dengan penghantaran hadiah daripada kedua-dua belah pihak.

\section{Keperibadian Warkah L}

Pada tanggal 30 September 1798 bersamaan dengan 19 Rabiulakhir 1213, warkah ini telah dihantar ke Belanda dan diterima pada 19 Oktober 1798. Paduka Sri al-Sultan Bima telah menghantar warkah kepada Paduka Tuan Gurnadur Jenderal sebagai balasan kepada warkah yang dihantar oleh Yang 
Maha Mulia pada tahun 1797. Dalam warkah ini jelas menunjukkan bahawa Sultan Bima telah memberi taat setia dan menyanjungi Yang Maha Mulia. Selain itu, sebagai langkah menjaga keselamatan negeri, kerajaan Bima telah menunjukkan taat setia dengan mendengar segala arahan daripada kerajaan Belanda termasuklah perihal alat-alat kebesaran kerajaan Sumbawa yang telah dirampas oleh Bima.

Kerajaan Bima melakukan perkara tersebut kerana kerajaan Sumbawa telah melanggar perjanjian dengan kerajaan Bima sehingga menimbulkan perasaan tidak puas hati. Namun begitu, kerajaan Bima telah mendapat arahan daripada Belanda untuk memulangkan kembali alatan yang telah dirampas tersebut. Selain itu, pihak Belanda telah menggunakan pengaruhnya untuk mendamaikan kedua-duah buah kerajaan tersebut bagi mengelakkan peperangan daripada berlaku. Kesannya, apabila Bima dan Sumbawa berdamai, Belanda telah menjadikan kerajaan tersebut sebagai hub negeri untuk perdagangan dan rakan kongsi. Sementara itu, fetor Adam van Rossem dilucutkan jawatan di Bima dan digantikan oleh Adriaan Vermeulen. Adriaan Vermeulen menjadi residen di Bima bermula pada tahun 1798 sehingga tahun 1801. Kandungan warkah ini juga menegaskan bahawa orang Bugis Makassar sangat tegas dan menimbulkan kegentaran pada pihak Bima. Oleh itu, raja Bima telah membuat kenyataan bahawa baginda ingin mengelak untuk berkerjasama dengan orang Bugis Makasar kerana khuatir akan ditindas, dan hak negeri akan diambil oleh mereka.

\section{Keperibadian Warkah $\mathbf{P}$}

Pada 3 Oktober 1800 merupakan tarikh warkah $P$ ditulis dan dihantar kepada Bima, iaitu bersamaan dengan 14 Jamadilawal 1415. Warkah ini diterima oleh Belanda pada 23 April 1801. Kandungannya menceritakan tentang Paduka Saudara Raja Bima yang memberi maklum kepada Tuan Syahbandar untuk mengirimkan perahu berserta khadam ke Betawi. Penghuraian warkah ini tertumpu pada hubungan persahabatan antara Tuan Syahbandar dengan Raja Bima yang baru berlangsung.

\section{Keperibadian Warkah Q}

Warkah Q ditulis pada 10 Jamadilawal 1216 bersamaan dengan 18 September 1801 yang dihantar oleh Bima kepada Belanda. Dalam warkah ini, dinyatakan tentang Inggeris yang telah membuat onar di muara sungai Betawi. Hal ini telah menimbulkan permasalahan yang serius kepada Betawi sehingga menyebabkan Tuan Edeler membuat keputusan untuk mengeluarkan kayu 
sepang ke Semarang. Selain itu, warkah ini juga menceritakan tentang Bima yang mempunyai masalah kekurangan dana untuk mengelola pentadbiran negeri.

Seterusnya, perihal kerosakan arloji juga diberitahu kepada Belanda dengan harapan untuk mendapatkan bantuan. Menurut Gunawan (2017), arloji bermaksud jam yang dipakai di tangan atau jam yang diletakkan di dinding. Selain itu, turut diceritakan tentang Raja Bima meminta bantuan dari segi ubat, senapang dan timah.

\section{Keperibadian Warkah V}

Pada 21 September 1802 bersamaan dengan 23 Jamadilawal 1217, warkah ini telah dihantar ke negeri Belanda. Warkah ini sampai pada 12 Oktober 1802 di negeri Belanda dan diterima oleh Yang Maha Mulia. Warkah ini lebih berkisar tentang kayu sepang yang akan dihantar kepada kerajaan Belanda setelah berkali-kali meminta kayu tersebut. Fungsi kayu sepang ini adalah untuk pembinaan rumah atau istana. Selain itu, kandungan warkah juga mengandungi cerita negeri Bima yang dilanggar oleh bajak.

\section{Keperibadian Warkah W}

Pada 2 September 1803 bersamaan dengan 15 Jamadilawal 1217 Warkah W ini dihantar kepada kerajaan Belanda. Tarikh tepat warkah sampai tidak dapat diketahui namun berfokus kepada bulan Oktober 1803 dan ditulis pada malam ke-17 Ramadhan. Warkah ini berkisar tentang pembelian meriam sebanyak 28 buah yang sudah ditempah daripada negeri Semarang. Raja Bima telah meminta bantuan agar sebuah perahu besar dapat dihantar ke Semarang dan mengambil meriam tersebut. Namun begitu, setelah setahun, kapal besar itu masih juga belum kembali ke bumi Bima. Oleh itu, Raja Bima menyangka kapal tersebut rosak atau masih lagi menunggu dan belum pulang.

\section{Keperibadian Warkah G7}

Warkah ini dihantar kepada Belanda pada tarikh 21 Julai 1820 bersamaan dengan 10 Syawal 1235. Namun begitu, Warkah G7 ini agak pelik kerana merupakan satu-satunya warkah yang tiada tarikh diterima oleh Belanda. Warkah ini disimpan dengan menggunakan kod tersendiri, iaitu Cod. Or.2223 (81) dan warkah ini mempunyai salinan Ja'in Abdurrahman yang telah dirumikan oleh Van Schelle. Warkah ini memuatkan maklumat tentang balasan hadiah daripada Bima kepada kerajaan Belanda. Warkah ini merupakan warkah yang paling pendek dan berkisar tentang pujian berserta 
hadiah. Panjangnya hanya merangkumi 11 baris dan 3 ayat sebagai penutup warkah-warkah sebelumnya.

Sembilan warkah ini ialah catatan sejarah hubungan antara kerajaan Bima dan Belanda dan menonjolkan kaedah diplomatik yang digunakan oleh Sultan Abdul Hamid. Penelitian dalam penulisan ini adalah untuk menganalisis jenis iringan hadiah dalam warkah yang diutuskan oleh kerajaan Bima kepada Belanda.

\section{PEMBERIAN HADIAH SEBAGAI TANDA PERSAHABATAN}

Setiap hubungan yang terjalin sama ada menerusi politik, sosial, dan ekonomi bergantung pada kehendak yang ingin dicapai oleh pemerintah yang menawarkan hubungan. Begitu juga yang berlaku pada hubungan antara Bima dan Belanda. Setiap kali warkah yang diutus kepada Belanda mahupun yang diterima oleh Bima, sudah pasti mempunyai motif penyampaian masingmasing yang diperhalusi dengan sebaik-baiknya agar memberi kesan positif untuk mengelakkan kesalahfahaman. Dalam Teori Diplomasi Islam, hubungan diplomatik bukan sahaja menekankan hubungan semata-mata namun kaedah penyampaian turut memainkan peranan penting. Ketidaksesuaian mekanisme yang diaplikasikan boleh mendatangkan kemudaratan. Menurut Ahmad dan Tjoki (2018) untuk menjalani hubungan berdiplomasi, peranan ketua perwakilan sangat penting bagi memastikan matlamat yang diingini tercapai demi kebaikan kedua-dua belah pihak. Oleh itu, faktor adab dan etika merupakan perkara yang perlu diambil kira oleh seorang ketua diplomat yang dilantik semasa berada di negara yang dilawatinya.

Sudah menjadi kelaziman dalam mana-mana perjanjian perhubungan, perdagangan akan mewujudkan aktiviti pemberian hadiah. Pendek kata, hadiah merupakan kunci utama yang dibingkiskan bersama-sama dengan kiriman warkah. Pada zaman kesultanan Melayu, pemberian hadiah merupakan antara medium yang digunakan oleh pemerintah sebagai iringan warkah diplomatik. Hal ini juga berkaitan dengan adat Melayu, apabila mereka berziarah akan membawa hadiah sebagai buah tangan seperti buah-buahan, lauk-pauk dan sebagainya. Menurut Ahmed (2009) dalam Teori Diplomasi Islam, pemberian hadiah ialah tradisi yang diaplikasikan untuk menunjukkan hubungan mesra antara negara dan merupakan antara mekanisme utama dalam hubungan diplomatik antara kerajaan. Sementara itu, Gallop (1994) pula mengatakan bahawa bingkisan selalunya dihantar pada peringkat permulaan hubungan mesra antara kedua-dua pihak. Oleh itu, penulisan ini akan membincangkan jenis iringan hadiah oleh kerajaan Bima kepada kerajaan Belanda. 
Dalam warkah yang dikirim kepada Belanda, Sultan Abdul Hamid telah menghantar beberapa hadiah sebagai tanda ikatan dengan Belanda selain sebagai tanda penghargaan bagi memastikan hubungan yang terjalin menerusi ekonomi, politik dan sosial dapat berjalan dengan lancar. Hal ini juga membuka ruang kepada Bima menjadi antara kerajaan yang mendapat kepercayaan daripada Belanda. Pemberian hadiah bukan sahaja dapat mengeratkan hubungan tetapi juga berfungsi untuk membina kepercayaan kedua-dua pihak. Mohd Syazwan (2019) mengatakan bahawa Negeri-negeri Melayu Bersekutu telah memberikan kapal perang sebagai hadiah kepada British dengan tujuan untuk mengukuhkan hubungan kedua-dua kerajaan. Sufian dan Ahmad Kamal Ariffin (2017) pula berpendapat bahawa pemberian hadiah ialah bukti kedua-dua buah negara mempunyai hubungan yang baik dan merupakan simbol perlindungan kepada negara naungan. Di samping itu, pemberian hadiah juga bertujuan sebagai pengukuh empayar perniagaan dan benteng pertahanan di lautan. Hal ini menunjukkan bahawa dalam sesuatu perhubungan, pemberian hadiah merupakan perkara yang dapat memberikan aura positif demi memastikan peperangan atau rampasan kuasa dapat dielakkan. Berdasarkan pendapat sarjana di atas, jelas menunjukkan kerajaan Bima mengambil inisiatif dengan memberikan hadiah sebagai strategi untuk kelangsungan hubungannya dengan Belanda.

Antara iringan hadiah yang dikenal pasti dinyatakan dalam warkah Bima kepada Belanda adalah seperti yang berikut:

\section{Hamba Abdi}

Pada Warkah B, dinyatakan bahawa Bima telah menghadiahkan hamba abdi kepada Belanda untuk mengukuhkan hubungan dari sudut ekonomi. Hadiah tersebut ialah enam orang hamba abdi lelaki. Namun begitu, hadiah tersebut tidak dibawa pulang oleh kapitan kapal yang bernama Karel Mulder. Untuk mengelakkan salah faham, Sultan Abdul Hamid telah memaklumkan hal tersebut dalam warkah ini. Hal ini selari dengan Teori Diplomasi Islam yang menekankan adab semasa menjalinkan hubungan untuk mengelakkan perselisihan faham.

\footnotetext{
... keadaan enam orang abdi laki-laki yang tiada sepertinya. Maka yang seperti seperti kuda itu telah disediakan oleh Paduka Raja Bima, mau dikirimkan kepada Tuan Gurnadur Jenderal dengan segala Rat Van [In]dia ..., akan tetapi tidak mau dibawa oleh kapitan kapal punya nama Karel Mulder di atas kapal bernama Stavenisse adanya.
} 
Kebiasaannya, penulisan dalam warkah seperti ini meletakkan hamba sebagai pemberian hadiah paling utama sebelum disusuli dengan pemberian lain. Hamba juga terdiri daripada dua gender sama ada kesemuanya hamba lelaki, hamba perempuan ataupun percampuran gender. Menurut Awg Asbol (2011) pemberian hadiah kepada mereka yang lebih berkuasa merupakan perkara yang wajib dilakukan oleh negeri-negeri kecil yang ingin mendapatkan perlindungan daripada kerajaan yang lebih besar. Selain itu, pemberian hadiah juga adalah sebagai simbol persahabatan untuk menjadikan hubungan tersebut lebih erat. Pemberian hadiah ini juga dapat menjana ekonomi yang memberikan pulangan yang menguntungkan kepada kuasa-kuasa besar.

Warkah D dilihat sebagai warkah yang unik kerana pemberian hadiah yang diberikan oleh kerajaan Bima sebanyak dua kali pada tahun yang sama. Pada kali pertama, hadiah yang diberikan terdiri daripada enam orang hamba abdi perempuan dan enam orang hamba abdi lelaki. Pada ketika itu, perhubungan antara Bima dan Belanda ini sudah pun memasuki fasa kukuh sehingga kerajaan Bima menghantar hadiah dalam bilangan hamba yang ramai. Buktinya:

Syahdan diiringi dengan ini surat yaitu enam orang abdi perempuan dan enam orang abdi laki-laki ... upama daun kayu yang kering jua di tengah padang adanya.

Hamba mempunyai banyak gelaran dan bergantung pada pemerintah sesebuah negara untuk memberikan gelaran tersebut. Rasulullah SAW menggelarkan hamba bagi golongan lelaki dengan panggilan fata. Menurut Siti Arbaiyah (2015), penggunaan nama panggilan fatiya, yafta dan fatan bermaksud pemuda, orang muda dan hamba laki-laki. Sementara istilah hamba abdi sama maksudnya dengan panggilan amah atau nama lainnya dalam al-Quran sebagai Ima atau Amwah. Perkataan atau panggilan amah itu hanyalah panggilan khas yang diberikan kepada hamba abdi perempuan. Oleh sebab maksud amah itu bukanlah maksud yang baik, Rasulullah SAW memerintahkan gelaran amah itu ditukar kepada fatat yang bermaksud pemudi. Merujuk Warkah D ini, istilah hamba abdi digunakan dan berfungsi sebagai pembantu yang melaksanakan segala suruhan tuannya.

Seterusnya, penghantaran hadiah kali kedua oleh kerajaan Bima pada bulan Safar yang terdiri daripada empat orang hamba abdi lelaki dan dua orang hamba abdi perempuan yang diberikan kepada Kapitan De Groot. 
Syahadan ... Paduka Raja Bima mempersembahkan empat orang abdi laki-laki kecil dan dua orang abdi perempuan kecil yang tiada dengan sepertinya.

Pemberian hamba abdi sebanyak 18 orang oleh Bima kepada Belanda ini menandakan hubungan yang terjalin antara kedua-dua buah kerajaan ini adalah mantap. Selain itu, terdapat simbolik dalam pemberian ini yang dapat dilihat, iaitu perkaitannya dengan aktiviti perdagangan hamba yang sangat aktif selain masyarakat yang ingin meningkatkan taraf hidup dan keluar daripada kemiskinan. Ismail (2016) menyatakan bahawa terdapat banyak maksud perhambaan dan penggunaan khidmatnya mengikut pemerintah yang menjalankan aktiviti perhambaan tersebut. Sementara itu, menurut Bazrul (2015) kemewahan seseorang dapat diukur melalui pemilikan hamba abdi yang ramai.

Selain Warkah D, kandungan Warkah L turut menyatakan pemberian hadiah berupa hamba abdi kepada Belanda: "Persembahkan ke bawah Duli Hadirat Yang Maha Mulia, yaitu ... dan empat orang abdi laki-laki ...”.

Petikan tersebut menunjukkan sultan Bima memberikan buah tangan, iaitu empat orang abdi kepada Belanda. Sultan Bima dilihat dengan senang hati memberikan rakyatnya sebagai hamba untuk menunjukkan tanda taat setia kepada kerajaan Belanda. Hal ini selari dengan pendapat Salmah Jan (2014) yang menyatakan pemberian hamba kepada kerajaan yang lebih kuat dan kuasanya lebih besar adalah sebagai tanda taat setia dalam perhubungan dan juga sebagai taat setia kepada pemerintah yang berkuasa. Hal ini jelas menunjukkan bahawa sultan Bima sangat mentaati kerajaan Belanda yang sangat berkuasa pada ketika itu.

Warkah Q dan V juga mencatatkan rekod bahawa kerajaan Bima, iaitu Sultan Abdul Hamid menghadiahkan hamba kepada utusan untuk dipersembahkan kepada Belanda. Cenderamata ini dilihat sebagai perantara kepada kerajaan Belanda untuk lebih mengenali sosial dan kehidupan golongan pemerintah Bima, kerana hamba ini akan hidup bersama-sama pemerintah Belanda dan menjalankan pekerjaan serta bergaul dengan masyarakat setempat. Setiap hamba yang dihantar akan dipilih sebaik mungkin oleh sultan Bima agar dapat memberikan konotasi yang baik tentang kerajaan Bima itu sendiri. Oleh itu, kerajaan Belanda dapat menilai dan membuat ukuran tentang keperibadian sultan Bima hanya melalui hamba yang diberikan bersama-sama dengan utusan tersebut. Cerminan rakyat ialah cerminan rajanya. Pemilihan hamba ini berfokuskan pada hamba yang berkualiti dan menjaga adab sopan kerana perkara ini penting untuk mengelakkan atau tidak 
menimbulkan isu serta masalah pada masa akan datang. Bukti pemberian hamba abdi sebagai hadiah dalam Warkah Q dan V dapat dilihat melalui pernyataan ringkas di bawah:

\section{Warkah Q}

Syahdan adalah Paduka Raja Bima mempersembahkan kepada Duli Hadirat Paduka Yang Maha Mulia dua abdi laki-laki kecil ...

\section{Warkah V}

Lagipun pada waktu sekarang adalah Paduka Raja Bima dengan sekalian wazir al-menterinya mempersembahkan ke bawah Duli Hadirat Paduka Yang Maha Mulia, yaitu enam orang abdi laki-laki ...

Hamba abdi ini berfungsi untuk melakukan pelbagai pekerjaan untuk tuannya. Hai ini dapat dikaitkan dengan situasi kerajaan Belanda yang dapat menggunakan hamba tersebut dengan tujuan memenuhi keperluan dalam pelbagai bidang yang mampu menjana ekonomi negara. Hamba lelaki bermanfaat dalam bidang pertahanan untuk wilayah dan negeri mereka. Menurut Anon (2007), hamba lelaki memainkan peranan yang sangat besar kepada negeri yang dinaungi. Hamba lelaki berfungsi sebagai pertahanan untuk kerajaan yang dinaungi. Walaupun mereka dilihat sebagai bahan untuk dijual beli namun hal ini merupakan perkara biasa yang terjadi ketika zaman pemerintahan raja-raja Melayu dahulu.

Apabila dilihat kembali, sembilan warkah Bima yang dihantar kepada Belanda, Warkah W merupakan warkah yang terakhir tentang pemberian hamba kepada kerajaan Belanda. Dalam warkah ini, sultan Bima menghadiahkan dua orang hamba abdi kepada Belanda namun tidak dinyatakan secara tepat jantina dan umur hamba tersebut. Buktinya dapat dilihat melalui petikan pendek Warkah W seperti yang berikut: "Surat akan mempersembahkan ke bawah Duli Hadirat Yang Maha Mulia, yaitu ... dan dua orang abdi ...".

Dalam pada itu, terdapat kelainan melalui pengiriman sembilan warkah ini, iaitu kehadiran warkah yang memberikan buah tangan kanak-kanak sebagai tanda perhubungan. Jumlah yang diberi sangat ramai, iaitu 12 orang kanak-kanak termasuk lelaki dan perempuan seperti yang dinyatakan pada warkah yang berikut: "Mempersembahkan kepada Tuan Yang Maha Mulia yaitu lima budak perempuan dan tujuh budak laki-laki ...".

Menurut Hamidin (2005), salah satu sumber ekonomi bagi negara Barat seperti Belanda, Sepanyol dan Portugal pada abad ke-15 ialah aktiviti 
perhambaan. Aktiviti perhambaan atau perdagangan hamba untuk kuasa ekonomi utama ini sangat penting sehingga mampu mewujudkan pembukaan "Dunia Baru" pada abad tersebut. Oleh yang demikian, semakin ramai hamba yang diberikan kepada kerajaan Belanda semakin erat perhubungan yang dibina bahkan memberikan keuntungan kepada Belanda pada ketika itu. Walaupun aktiviti perhambaan ini agak menjengkelkan namun, bagi masyarakat Melayu kegiatan atau aktiviti perhambaan ini merupakan satu cara untuk melepaskan diri daripada kemiskinan yang membelenggu kehidupan. Menurut Khairul Ashraf (2018), hamba Melayu tidak akan dijadikan sebagai hamba tanpa sebab. Mereka dijadikan sebagai hamba abdi untuk membalas jasa tuan mereka yang memberikan makanan, tanah, tempat tinggal, jaminan keselamatan dan tanggungan harfiah serta lahiriah. Walaupun menjadi seorang hamba bukanlah mudah tetapi cara ini mampu menjamin kehidupannya.

\section{Lilin}

Terdapat enam warkah Sultan Abdul Hamid, iaitu Warkah D, L, Q, V, W dan G7 yang menyebut tentang pemberian lilin. Lilin dijadikan antara bahan utama untuk mengeratkan hubungan antara kerajaan Bima dan Belanda kerana kegunaan lilin yang sangat bermanfaat antaranya sebagai sumber cahaya pada waktu malam, di samping dijadikan sebagai bahan kalis air untuk kertas penting kerajaan, selain sebagai tempat menyimpan jarum agar tidak berkarat, serta dapat dijadikan sebagai bahan hiasan yang diukir dengan cantik dan menarik.

Sebelum abad ke-19, lilin yang digunakan untuk aktiviti perdagangan atau hadiah merupakan lilin yang diperbuat daripada lemak lembu yang kental atau lemak mana-mana haiwan yang dilihat bersesuaian untuk tujuan tersebut. Bukti pemberian lilin sebagai hadiah dapat dilihat melalui Warkah D:

Syahdan diiringi dengan ini surat ... dan dua pikul lilin yang tiada dengan sepertinya, umpama daun kayu yang kering jua di tengah padang adanya.

Apabila diamati, pemberian lilin ini seperti perkara menjadi kemestian kepada Bima untuk dihadiahkan kepada Belanda di samping bertujuan untuk merapatkan lagi ukhwah. Selain itu, terdapat makna tersirat atau simbolik yang dikenal pasti melalui pemberian ini, iaitu Bima sedia menghulurkan bantuan sekiranya Belanda menghadapi masalah.

Dalam Warkah L, menceritakan permasalahan antara kerajaan Bima dengan Belanda, iaitu apabila kayu sepang yang diminta oleh kerajaan 
Belanda tidak dapat dipenuhi oleh Bima kerana fizikal perahu yang agak kecil tidak dapat menampung kuantiti yang banyak. Permohonan maaf telah dibuat oleh Sultan Abdul Hamid serta menteri baginda meminta fetor untuk menyampaikannya kepada ke bawah Hadirat Yang Maha Mulia agar tidak berkecil hati. Selain itu, terdapat perkara lain yang mungkin boleh menimbulkan salah faham kepada Belanda, iaitu tentang pertukaran fetor Adam van Rossem kepada Adrian Vermeulan yang dilakukan oleh sultan Bima. Pemberitahuan tentang hal ini juga menjadi antara kandungan penting dalam warkah dan selari dengan Teori Diplomasi Islam yang mementingkan adab, etika dalam menjaga keharmonian hubungan antara kerajaan. Oleh itu, dapatlah ditafsirkan bahawa pemberian lilin ini adalah sebagai pencerahan kepada masalah tersebut agar tidak menjadi semakin rumit.

Syahdan adalah pada waktu sekarang Paduka Raja Bima ada persembahkan ke bawah Duli Hadirat Yang Maha Mulia. ... dan dua pikul lilin yang tiada dengan sepertinya adanya.

Warkah seterusnya daripada Bima ialah Warkah $Q$ yang juga menerangkan tentang pemberian sebanyak dua pikul lilin sebagai hadiah kepada kerajaan Belanda. Dalam warkah ini, sultan Bima memberikan penerangan kepada Belanda bahawa kerajaan Bima sedang menghadapi masalah. Masalah utama yang diketengahkan ialah mengenai kayu sepang yang sudah digunakan oleh negeri Semarang ketika Inggeris menyerang Semarang. Pengeluaran kayu sepang ini mengikut arahan Tuan Edeler yang memerintah Semarang pada ketika itu. Rentetan daripada perkara ini telah menimbulkan isu kekurangan kayu sepang di Semarang. Selain itu, masalah lain yang dihadapi oleh kerajaan Bima ialah mengenai arloji yang rosak dan meminta ihsan kerajaan Belanda untuk mendapatkan pakar bagi membaiki arloji tersebut. Oleh itu, simbol tersirat melalui pemberian lilin ini adalah untuk kerajaan Belanda memenuhi permintaan Bima kerana bantuan tersebut seakan-akan memberikan sinar harapan kepada kerajaan tersebut.

Syahdan adalah pada waktu sekarang Paduka Raja Bima ada persembahkan ke bawah Duli Hadirat Yang Maha Mulia. ... dan dua pikul lilin yang tiada dengan sepertinya adanya.

Seterusnya, dalam Warkah V dinyatakan sebanyak tiga pikul lilin dihadiahkan oleh kerajaan Bima kepada kerajaan Belanda. Buah tangan ini diberikan pada 10 Jamadilawal 1216 bersamaan dengan 18 September 1801. 
Pada masa ini, kerajaan Bima menghadapi masalah kewangan. Oleh itu, pihak kerajaan Bima telah mengirimkan kayu sepang kepada Belanda dengan melantik Bumi Parisi Bolo dan tiga orang juragan sebagai penghantar kayu sepang tersebut. Sehubungan dengan itu, Sultan Abdul Hamid mengharapkan bahawa hasil kayu sepang itu dapat ditukarkan dengan senapang, ubat dan timah sebagai simpanan untuk menghadapi cabaran dan masalah lanun yang dihadapinya. Dalam warkah ini juga, terdapat aktiviti jual beli kayu sepang yang dilakukan oleh kerajaan Bima.

Sekarang adalah Paduka Raja Bima dengan sekalian wazir almenterinya mempersembahkan ke bawah Duli Hadirat Paduka Yang Maha Mulia, yaitu ... dan tiga pikul lilin yang tiada dengan sepertinya seupama daun yang kering di tengah padang jua adanya.

Sementara itu, melalui Warkah W, kerajaan Bima telah menghadiahkan sebanyak dua pikul lilin:

Syahdan adalah Paduka Raja Bima diiringi dengan ini surat akan mempersembahkan ke bawah Duli Hadirat Yang Maha Mulia, yaitu $d[u a]$... dan dua pikul lilin yang tiada dengan sepertinya melainkan diperbanyak-banyak maaf dan rahim Paduka Yang Maha Mulia jua adanya.

Warkah ini menceritakan perasaan dukacita Sultan Abdul Hamid dengan permasalahan yang dihadapi oleh baginda kerana sebanyak 28 buah meriam yang dibeli daripada Belanda belum lagi diperoleh. Baginda menzahirkan kekhuatiran sekiranya kapal yang membawa meriam tersebut rosak ataupun telah dirompak. Oleh itu, sultan Bima meminta agar kerajaan Belanda dapat memberikan meriam yang lain dan baginda akan membayarnya. Pada masa ini, pemberian hadiah lilin juga agak sedikit kuantitinya berbanding warkah yang lain.

Warkah G7 juga merekodkan sebanyak 50 pikul lilin antara hadiah yang diberikan kepada Belanda. Warkah terakhir ini agak ringkas namun padat isinya yang turut menggambarkan hubungan rapat dan mesra antara kerajaan Bima dan Belanda seperti yang dinyatakan dalam warkah ini, iaitu pemberian tersebut adalah sebagai tanda persahabatan sehidup semati dengan Belanda. Warkah ini menunjukkan bahawa Sultan Abdul Hamid mengharapkan hubungan yang terbina ini sentiasa berpanjangan. Buktinya:

Kita berkirim barang-barang sedikit akan buat tanda hidup sahabat bersahabat dan bingkisan-bingkisan itu kepada Tuan 
Besar sendiri, ... lima puluh pikul lilin ... akan tanda sahabat bersahabat dari beberapa zaman juga adanya.

Oleh itu, dapat dinyatakan di sini bahawa pemberian hadiah berupa lilin merupakan salah satu cara kerajaan Bima mengetengahkan permasalahan kepada pihak Belanda. Permasalahan dan permintaan kerajaan Bima diterjemahkan dalam nada sopan bagi memastikan kerajaan Belanda tidak terkesan atau berkecil hati dengan isu yang diketengahkan seperti yang ditekankan dalam Teori Diplomasi Islam bahawa adab dan etika semasa menjalinkan hubungan diplomatik adalah sangat penting untuk mengukuhkan hubungan dan seterusnya mengelakkan perselisihan faham. Hasilnya, kerajaan Belanda dapat memahami masalah dan situasi yang dialami oleh Bima.

\section{Haiwan yang Tangkas}

Sudah menjadi kelaziman sebagai pemerintah kesultanan Melayu memberikan hadiah sebagai tanda persahabatan. Hal ini dapat dilihat apabila kerajaan Bima telah memberikan pelbagai hadiah kepada kerajaan Belanda. Antara hadiah yang diberikan oleh Sultan Abdul Hamid ialah haiwan yang tangkas, iaitu kuda. Kuda merupakan haiwan yang sangat terkenal dengan ketangkasannya selain harganya yang sangat lumayan dan merupakan haiwan berkategori elit yang hanya dimiliki oleh golongan bangsawan. Menurut Azharudin (2013), tradisi Melayu menggambarkan bahawa kuda dan gajah merupakan haiwan elit dan hanya digunakan oleh golongan bangsawan. Haiwan ini sangat berharga dan mendapat perhatian, merupakan haiwan istimewa dan dijadikan hadiah yang bernilai. Di samping itu, haiwan ini juga dijadikan sebagai kenderaan perang dan juga semasa beriadah. Apabila diteliti daripada warkah-warkah kiriman Sultan Abdul Hamid, baginda kerap menghadiahkan kuda kepada Belanda. Buktinya:

Warkah E

Syahdan adalah Paduka Raja Bima persembahkan kepada Tuan Yang Maha Mulia yaitu ... dan dua pasang kuda merah tua dan dua pasang kuda kelabu dan dua pasang lagi kuda kelabu putih.

\section{Warkah L}

Persembahkan ke bawah Duli Hadirat Yang Maha Mulia, yaitu lima pasang kuda kelabu itam dan satu pasang kuda kelabu itam jua tetapi lebih putih rambutnya menjadi enam pasang kuda dan ... 
Warkah Q

Mempersembahkan ... dan sepasang kuda kelabu putih, dan sepasang kuda kelabu dauk dan ...

Warkah V

Lagipun pada waktu sekarang adalah Paduka Raja Bima dengan sekalian wazir al-menterinya mempersembahkan ke bawah Duli Hadirat Paduka Yang Maha Mulia ... dan tiga pasang kuda hitam dan tiga pasang kuda kelabu ...

Warkah W

Dipersembahkan ke bawah Duli Hadirat Yang Maha Mulia, yaitu ... dan dua pasang kuda ...

\section{Warkah G7}

Bingkisan-bingkisan itu yang kepada Tuan Besar sendiri, dua pasang kuda hitam dan dua pasang kuda dauk ...

Menurut Azharudin (2014) pemberian kuda mempunyai maksud tertentu, dan melambangkan suatu tindakan untuk memperkuat sesebuah kerajaan agar tidak tumpas di tangan lawan musuh. Hal ini ada kaitannya dengan perilaku luaran kuda yang sangat tangkas berlari dan bertenaga yang menggambarkan keadaan hubungan semasa kerajaan Bima dan kerajaan Belanda. Pemberian hadiah seperti ini menimbulkan satu tamsilan bahawa pemberian haiwan tangkas seperti kuda mempunyai maksud yang perlu diperhalusi oleh kerajaan Belanda terutamanya dari segi komitmen bersama untuk menghadapi segala cabaran pentadbiran.

\section{KESIMPULAN}

Sembilan warkah diplomatik Sultan Abdul Hamid ini menggambarkan kaedah yang digunakan oleh baginda untuk mengekalkan hubungan dengan kerajaan Belanda. Warkah tersebut ialah Warkah B (20 Julai 1790), D (23 Julai 1792), $E$ (25 Ogos 1792), $L$ (30 September 1798), $P$ (3 Oktober 1800), $Q(18$ September 1801), $V(21$ September 1802), $W$ (2 September 1803) dan $G 7$ (21 Julai 1820). Melalui penelitian, pemberian hadiah merupakan kaedah dominan yang digunakan untuk tujuan tersebut. 
Antara hadiah yang dikenal pasti diberikan oleh Bima kepada Belanda termasuklah hamba abdi atau khadam yang terdiri daripada golongan dewasa dan kanak-kanak lelaki dan perempuan dalam jumlah yang ramai diikuti dengan hadiah berupa lilin yang mempunyai simbolik pemberian. Seterusnya, haiwan tangkas seperti kuda juga dijadikan sebagai buah tangan kepada kerajaan Belanda. Inisiatif ini dilihat sebagai usaha Bima menterjemahkan keinginan atau kehendak untuk mencapai matlamat perdamaian dan pengukuhan diplomatik antara kedua-dua buah kerajaan. Penelitian ini juga membuktikan bahawa warkah yang merupakan catatan rekod tentang peristiwa diplomatik ini mampu dijadikan sebagai medium pengukuh hubungan. Oleh itu, pengkajian terhadap warkah perlu diperhebat agar perkara penting yang dicatatkan didalamnya dapat dikongsikan sebagai dapatan asli dan disebarluaskan kepada khalayak.

\section{RUJUKAN}

Ahmed Musa. (2009). Diplomacy: Theory and practice in Islam. Universiti Islam Antarabangsa.

Annabel TehGallop. (1994). The legacy of the Malay letter = Warisan warkah Melayu / Annabel Teh Gallop; with an essay by E. Ulrich Kratz. Malaysia: British Library for the National Archives.

Anon. (2007). Sejarah: Sistem perhambaan di Negeri-negeri Melayu. Diakses daripada http://rixercooperation.blogspot.com/2007/04/sejarahsistrm-perhambaandinegeri.html pada 1/03/2021.

Awg Asbol Mail. (2011). Kesultanan Melayu tradisional: Satu analisis kepada peranan Sultan dalam kegiatan ekonomi. Jurnal Darussalam, 11(1): 6-32.

Azharudin Mohamed Dali. (2013). Hubungan kuda dengan masyarakat Tanah Melayu sebelum merdeka satu penelitian sejarah sosio-budaya. Prosiding Seminar Antarabangsa Ke-2 Arkeologi, Sejarah dan Budaya di Alam Melayu Bilik Senat \& Bilik Majlis. Institut Alam dan Tamadun Melayu (ATMA) Universiti Kebangsaan Malaysia. hlm. 172-191.

Azharudin Mohamed Deli (2014). Kuda dalam masyarakat di Tanah Melayu pada era sebelum merdeka. Melayu: Jurnal Antarabangsa Dunia Melayu, 7(2), 172-191.

Bazrul Bahaman. (2015). Konsep rakyat dan peranannya dalam negara. Jurnal Peradaban Melayu, 10, 123-134.

Hamidin Abd Hamid. (2005). Emosi Melayu: Melayu dan perhambaan di CAPE, 1652-1838. Jurnal Pengajian Melayu, 16(1), 116-131.

Haris, Tawalinuddin (2006). Kesultanan Bima di Pulau Sumbawa. Wacana, 8(1), 17-31. Ismail Ali. (2016). Hegemoni lanun di perairan Kepulauan Borneo. Utusan Borneo. Diakses daripada http://eprints.ums.edu.my/13285/1/nc0000002861.pdf pada10/03/2021, 2:01 p.m.

Ismail Hamid. (1988). Masyarakat dan budaya Melayu. Dewan Bahasa dan Pustaka. 
Khairul Ashraf Muhamad. (2018). Sistem perhambaan Alam Melayu. The patriots. Diakses daripada https://www.thepatriots.asia/sistem-perhambaan-alammelayu/ pada $10 / 03 / 2021,2.44$ p.m.

M. Hilir Ismail. (2004). Peran Kesultanan Bima dalam perjalanan sejarah Nusantara. Mataram: Lengge.

Marwati Djoened Poesponegoro \& Nugroho Notosusanto. (2008). Sejarah nasional Indonesia III zaman pertumbuhan dan perkembangan kerajaan Islam di Indonesia. Edisi kedua, Bab 2 Pertumbuhan dan Perkembangan Kerajaankerajaan Islam. PT (Persero) Penerbitan dan Percetakan.

Mohd Shazwan Mokhtar. (2019). Agenda imperialis dalam krisis pentadbiran kolonial di Negeri-Negeri Melayu Bersekutu, 1921-1925. Jebat: Malaysian Journal of History, Politics \& Strategic Studies, 46(2): 28-55.

Morris, D.F. van Braam (1890), "Nota van toelichting behoerende bij bet contract gesloten met bet landschap Bima op den 20sten October, and de Regeering ingediend door den Gouverneur van Celebes en Onderhoorigheden", $\operatorname{dlm} T B G$ $35,176-233$.

Pulau Sumbawa News. (2015). Sejarah Bima. Diakses daripada https:// pulausumbawanews.net/index.php/2015/06/26/sejarah-bima/ Ppada 10/03/2021, 3.15 pm. Pulau Sumbawa News. Rouffaer, G.P., "Oudjavaansche lnscriptie van Soembawa", NBG, 48, 1910: 110-113.

Salmah Jan Noor Muhammad. (2014). Bingkisan hadiah pencetus keberlangsungan hubungan diplomatik pada zaman kesultanan Melayu. International Journal of the Malay World and Civilisation (Iman), 2(2): 91-103.

Siti Arbaiyah Mohd Saron. (2015). Hamba abdi menurut al-Quran dan kaitannya dengan isu pemerdagangan manusia. Diakses daripada https:/dokumen.tips/ docu ments/hamba-abdimenurut-al-quran-dan-kaitannya-terhadap-permasalahanpe merdaganganmanusia.html pada 10/03/2021, 1.30 p.m.

Sufian Mansur \& Ahmad Kamal Ariffin Mohd. Rus. (2017). Kegemilangan maritim Kesultanan Melayu Melaka. Penerbit Universiti Kebangsaan Malaysia.

Suryadi (2010) . Sepuluh Surat Sultan Bima Abdul Hamid Muhammad Syah, dalam Henri Chambert-Loir et al., Iman dan piplomasi. Serpihan sejarah Kerajaan Bima. Kepustakaan Populer Gramedia.

Tawalinuddin Haris, Susanto Zuhdi \& Triana Wulandari. (1997). Kerajaan tradisional di Indonesia: Bima. Diakses daripada http://repositori.kemdikbud.go.id/7488/1/ KERAJAAN\%20TRADISIONAL\% 20\%20DI\%20INDONESIA\%20BIMA. pdf pada pada 10/03/2021, $12.00 \mathrm{pm}$.

Tawalinuddin Haris. (2006). Kesultanan Bima di Pulau Sumbawa. Wacana, 8(2), 17-31. 